\title{
HISTOCHEMICAL STUDY ON VITAMIN D
}

\author{
MASAYA ARAKI, SHINTO CHIN AND KEIKA RYO \\ Department of Pathology, Kyoto Prefectural University School of \\ Medicine, Nishijin, Kyoto
}

(Received January 20, 1957)

The distribution and fate of vitamin $\mathrm{D}$ in living bodies have hitherto been little studied, though ricket has long been known to be due to vitamin $\mathrm{D}$ deficiency. This was probably so because the determination of vitamin $\mathrm{D}$ in biological materials was very difficult compared with other vitamins, and it seems natural that the histochemistry of vitamin $\mathrm{D}$ remains almost undeveloped.

It was achieved by the authors to observe the distribution of vitamin D in cells and tissues under fluorescence microscope by utilizing the primary fluorescence of the vitamin. The method as well as the pictures of vitamin $\mathrm{D}$ in tissues observed by this method will be described in this paper.

\section{EXPERIMENTAL}

\section{Materials and Methods}

Rats weighing approximately $150 \mathrm{~g}$ were used. After administering orally the vitamin, the animals were killed at various intervals and the tissues were examined histologically. As the vitamin, a crystalline calciferol preparation of Roche and Co. was used as an olive oil solution containing $20 \mathrm{mg}\left(80 \times 10^{3} \mathrm{I}\right.$. u. $)$ per $\mathrm{ml}$. 2.5-20 $\mathrm{mg}$ each was given by a stomach-tube $1-4$ times in succession.

\section{Method for Histochemical Observation}

The pieces of organs were fixed in $10-20$ per cent formalin for $30-60$ minutes, using a brown bottle to avoid the effect of light. The fixed pieces were washed in water for $10-30$ minutes. Frozen sections were then prepared and were observed under fluorescence microscope using $U_{V D}$ as a primary filter and $\mathrm{Y}_{2}$ as a secondary.

Observation: Vitamin D was detected as granules fluorescing yellowish, which were less resistant against ultraviolet light than those of vitamin A, disappearing in a few minutes.

\section{Critical Tests of the Method}

\section{Tests under Fluorescence Microscope}

Vitamin A is a fluorescing substance weakly resistant against ultraviolet light, but differs from vitamin $D$ in the following points. The fluorescence of vitamin $A_{1}, A_{2}$ and carotene is yellowish green, yellowish brown and light 
green, respectively, whereas that of calciferol is yellow. The fluorescence of vitamin $\mathrm{A}$ is more intensive than calciferol. Carotene is most resistant against ultraviolet light, hardly losing its fluorescence by irradiation for a relatively long time, whereas both vitamin $A_{1}$ and $A_{2}$ are less resistant and calciferol is the least resistant of all. The time of irradiation required for extinction of fluorescence of calciferol is about half that of vitamin A. For instance, using a $100 \mathrm{UV}$ mercury vapor lamp (MAZDA) as a light source, the fluorescence of carotene remains unchanged for 30 minutes, whereas that of vita$\min A_{1}$ and $A_{2}$ alcohols disappear in about 10 minutes, that of the ester forms of them in about 30 minutes but that of calciferol disappears in ca. 5 minutes. Taking these properties as index, vitamin D may be discriminated from vitamin A. Riboflavin fluoresces also yellowish green, but it is very resistant against ultraviolet light and is distributed diffusely in cells in stead of forming granules as in the case with vitamin A and D. Furthermore, when the slices are examined after treatment with organic solvents, e.g., ether, chloroform and alcohol, vitamin $\mathrm{D}$ is removed by extraction, losing its fluorescence. The differentiation between vitamin $\mathrm{A}$ and $\mathrm{D}$ is therefore quite easy.

\section{Tests by Chemical Reactions}

When $\mathrm{SbCl}_{3}$ is applied to a slice, vitamin A and carotene turn bluish, whereas vitamin D granules become orange-yellow. After adding glycerol dichlorohydrin $(\mathrm{GDH})$, vitamin $\mathrm{A}$ and carotene turn blue, whereas vitamin $\mathrm{D}$ from yellow to green. After adding $\mathrm{H}_{2} \mathrm{SO}_{4}$, vitamin $\mathrm{A}$ becomes blue at first, gradually turning to violet, while vitamin $\mathrm{D}$ granules are red at first, turning to dirty brown finally.

From these observations, it can safely be presumed that the yellowish fluorescent granules are derived from vitamin D. These observations are summarized in Table I.

TABLE I

Some Properties of Vitamin A, Carotene and Vitamin $\mathrm{D}_{2}$

\begin{tabular}{l|c|c|c}
\hline & Vitamin A & Carotene & Vitamin $\mathrm{D}_{2}$ \\
\hline Color & $\begin{array}{l}\mathrm{A}_{1} \text {, yellowish green } \\
\mathrm{A}_{2} \text {, yellowish brown }\end{array}$ & Green & Yellow \\
\hline $\begin{array}{l}\text { Resistance against } \\
\text { ultraviolet light }\end{array}$ & $\begin{array}{l}\text { W alcohol, ca. } 10 \mathrm{~min} \\
\text { A ester, ca. } 30 \mathrm{~min}\end{array}$ & Strong & $\begin{array}{l}\text { Extremely weak; } \\
\text { ca. 5 min }\end{array}$ \\
\hline $\mathrm{SbCl}_{3}$ reaction & Blue & Blue & Orange yellow \\
\hline $\mathrm{GDH}$ reaction & Blue & Blue & Yellow to green \\
\hline $\mathrm{H}_{2} \mathrm{SO}_{4}$ reaction & Blue to violet & Blue & Red to dirty brown \\
\hline
\end{tabular}




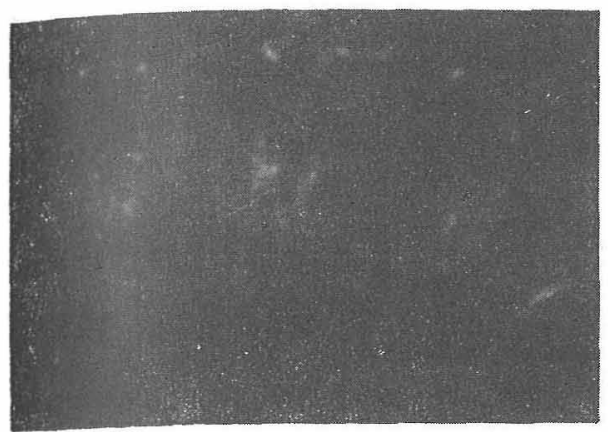

FIG. 1 Small Intestine 6 Hours after Administering Orally $10 \mathrm{mg}$ of Calciferol Fluorescence in the mucous epithelia of villi has almost disappeared and relatively large in size, fluorescent vitamin $D_{2}$ granules are detected in the central lacteals.

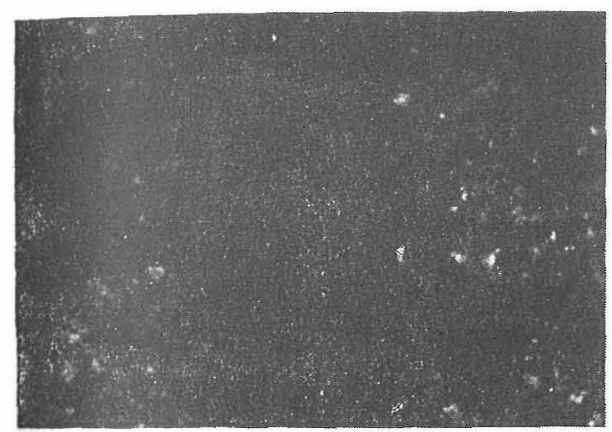

Fia. 2 Liver 24 Hours after Administering $5 \mathrm{mg}$ of Calciferol

Few vitamin $D_{2}$ granules are observed in the central part of the liver lobule, whereas they are markedly increased in the peripheral part. Almost all the vitamin is distributed in liver cells and scarcely any is found in Kupffer cells.

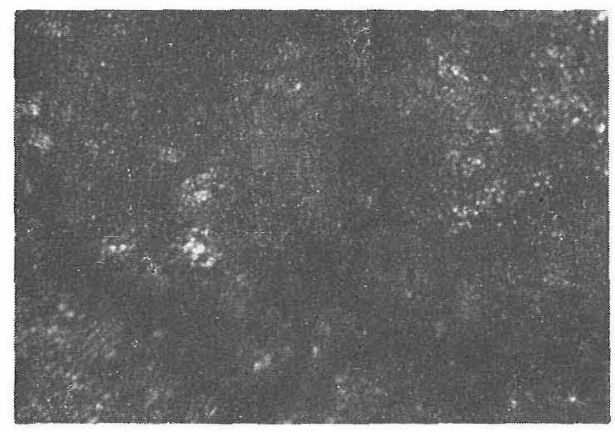

Fra. 3 Liver after Administering Twice $5 \mathrm{mg}$ of Calciferol

Vitamin $\mathrm{D}_{2}$ is diffusely distributed up to the central part of liver lobules, and the vitamin is detected mainly in liver cells.

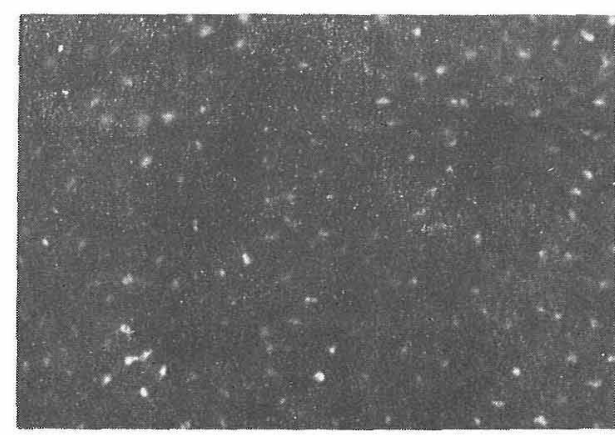

FIG. 4 Liver after Administering Four Times $5 \mathrm{mg}$ of Calciferol

Fine vitamin $D_{2}$ granules are seen diffusely in the liver cells of lobules. Besides, the uptake of the vitamin is also found in Kupffer cells. The vitamin granules in Kupffer cells are large, and intensively fluorescent.

Therefore, the fluorescence of the liver cells became unremarkable in the photograph by the predominating vitamin fluorescence in Kupffer cells.

\section{Results}

Histological Distribution of Vitamin D in Organs

Digestive Canal — The vitamin is difficult to detect in the stomach, but fairly well in the small intestine. In the jejunum and ileum it is hardly found one hour after an oral administration of the vitamin, but it can be detected well $2-3$ hours after the administration, viz. the vitamin is observed as fine granules in the mucous epithelia. The infiltration of the vitamin D 


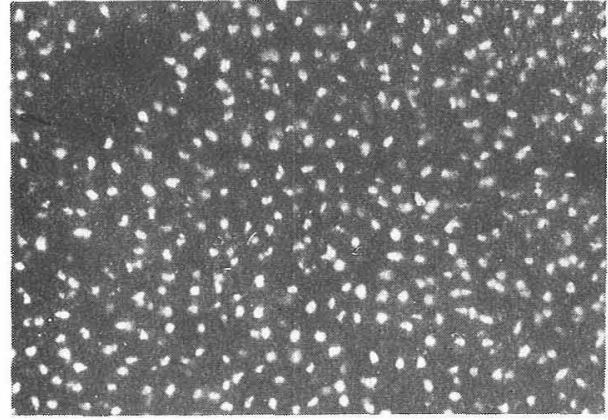

FIG. 5 Liver after Administering Four Times $10 \mathrm{mg}$ of Calciferol

Vitamin $\mathrm{D}_{2}$ distribution is so marked in Kupffer cells that the fluorercence of the liver cells can scarcely be observed.

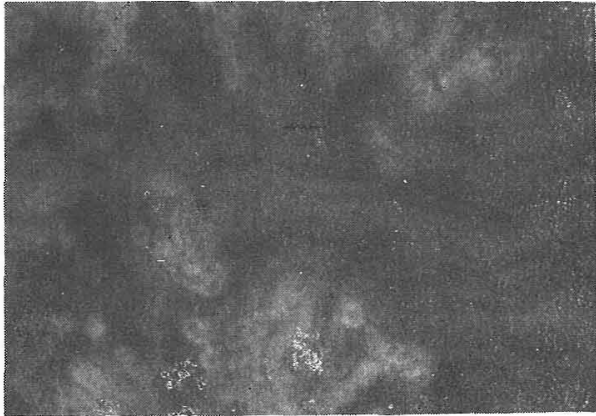

Fia. 6 Kidney 24 Hours after Administering Once $15 \mathrm{mg}$ of Calciferol

Vitamin $\mathrm{D}_{2}$ can not be detected in the renal corpuscles but markedly in the uriniferous tubules.

was observed in the submucous layer and central lacteals, the granules of the vitamin being larger and more intensely fluorescent in these regions. This suggests that the esterification of vitamin D with fatty acids; takes place there, as is the case with vitamin A (2), as shown in Fig. 1. Vitamin D enters thus into the blood vessels through the lymph vessels. In the duodenum the picture of the absorption of the vitamin was not remarkable, possibly due to the difficult absorption of the vitamin dissolved in oil owing to an insufficient mixing of the vitamin with bile and intestinal juice.

Generally speaking, the absorption picture of the vitamin from the intestinal canal become unremarkable after 12 hours. After 24 hours the vitamin was scarcely detectable in the mucous epithelia, but yet detectable in lymph vessels of the muscle layer, in the subserous cavity and in the central lacteals. It was especially pronounced when a large amount of the vitamin was administered. In this case vitamin D granules were sometimes detectable in both the mucus secreted from mucous epithelia, suggesting that the poor distribution of the vitamin in mucous epithelia are due to the secretion of the vitamin from the mucous epithelia, i.e., vitamin $\mathrm{D}$ may be assumed to be excreted from the intestinal canal. After parenteral administration of the vitamin almost the same pictures were also obtained, the details of which will be dealt with later. In the large intestine, the absorption of the vitamin was scarcely detected, possibly due to the function of the large intestine of absorbing water only, and not vitamin in oil.

Liver - In the liver the distribution of the vitamin became detectable about 4 hours after administration. The amount of the vitamin in the liver varied considerably according to its amount loaded: After administering $2.5 \mathrm{mg}$ of the vitamin it appeared as fine granules in the cytoplasm of the liver cells in the peripheral part of the lobule, but not in Kupffer's cells. When $5 \mathrm{mg}$ of the vitamin $\mathrm{D}$ was administered, the vitamin granules of the peripheral parts of liver cells increased and the vitamin was also detected in 
the middle parts (Fig. 2). After loading with $10 \mathrm{mg}$ of the vitamin, the vitamin appeared even in the central parts of the lobules (Fig. 3) but the vitamin intake of the Kupffer cells was not remarkable. When the loaded amount exceeded $20 \mathrm{mg}$, the vitamin granules were markedly observed in Kupffer cells (Fig. 4 5). In this case the vitamin was sometimes detected in the bile duct. The vitamin granules in the Kupfer cells were large and fluoresced more intensively than those in liver cells. The resistance of the former against ultraviolet light was also greater than that of the latter; $i$.e., the fluorescence of the granules in liver cells disappeared in about 5 minutes by ultraviolet light irradiation, whereas those in Kupfer cells disappeared in 67 minutes, due to the esterification of the vitamin with fatty acids in the Kupffer cells. After loading with little vitamin, as stated above, the vitamin was taken up at first by liver cells and when the loaded amount of the vitamin exceeded the capacity of liver cells for taking up the vitamin, it appeared in Kupffer cells.

Pancreas The vitamin was not detected in pancreas parenchyma, whereas it was demonstrated in interstitial fatty tissues to coexist with fat of fatty cells, only when the loaded amount of the vitamin exceeded $10 \mathrm{mg}$.

Lungs Lungs were one of the organs in which the vitamin was readily detected; it was observed inevitably when more than $10 \mathrm{mg}$ of the vitamin was loaded. It was detectable histologically in the endothelium of capillary vessels, in the alveolar epithelium, in reticullar cells of lymph apparatus and sometimes also in pleura epithelium.

Heart The vitamin $\mathrm{D}$ could be detected neither in the mycocardium nor in the endocardium, but was well observed in fatty cells of the pericardium.

Spleen The vitamin was not found when less than $10 \mathrm{mg}$ of the vitamin was loaded. After administering more than $15 \mathrm{mg}$ of the vitamin, vitamin granules appeared in the endothelium of the venous sinus, splenic pulp and reticular cells of the white pulp.

Adrenal Glands The vitamin was not demonstrated in the medulla but was often detectable in the cortex; especially rich in zona fasciculata, followed by zona reticulosa, and least in zona glomerulosa. Adrenal glands were the organs in which the vitamin was most easily detected next to the liver, and the amount of the vitamin detected rose markedly according to the amount loaded, presumably due to the solubility of vitamin D) in the fatty granules which occur abundantly in the cortex.

Kidneys These are the organs, in which the vitamin is most abundant next to the liver, adrenals and lungs. The vitamin was found almost in all cases when more than $10 \mathrm{mg}$ of the vitamin was loaded. After loading with $10 \mathrm{mg}$, the vitamin appeared in the cortex. It became detectable in the medulla when more than $20 \mathrm{mg}$ was loaded. Histologically, it failed to be detected in renal corpuscles, and was observed only in uriniferous tubules (Fig. 6), in which it was particularly abundant in proximal convulted tubules, but it was also detectable in distal convulted tubules. After loading with much vitamin, it was also detected in the epithelium of collecting tubules and in the lumen, viz. vitamin $\mathrm{D}$ is assumed to be excreted not only from the intestine but also from the kidneys. 
Adipose Tissues - The peripheral fatty tissues around the kidneys, eyeballs and subcutaneous adipose tissues were examined. The vitamin was detected in all the tissues when about $15 \mathrm{mg}$ was loaded. It was observed diffusely in cells, dissolved in the lipid of fatty cells.

Bone - The vitamin was proved in fatty and reticular cells of the marrow. The distribution of the vitamin in bone substance and in epiphyseal line is now under investigation.

Eyeballs — The vitamin was often detected in the adipose tissues around eyeballs as described above but it was hardly proved in any part of eyeballs except for chorioid. In chorioid, it was detected in the endothelium, adventitial cells and fibrocytes of blood vessels, suggesting the coxistence of the vitamin with adipose globules in this part. It was not detected in the retina, differing from vitamin A.

\section{DISCUSSION}

\section{On Histochemical Methods.}

Seeger (2) tried to detect vitamin D in streak preparations of the ascites from a carcinoma patient by applying to histochemistry of the methods of Brückner, Shear and Halden. He reported to have found positive granules in cells but the specificity of the method which he used is questionable, and is not accepted by most histochemists. Lison (3) emphasized in his book the necessity of a new departure for histichemical detection of vitamin D. A new fluorescence-microscopic detection method of vitamin D was deviced by the authors and clear histochemical pictures of the vitamin were obtained for the first time. Judging from the fluorescence-microscopic properties of the vitamin $\mathrm{D}$ granules, as was described in the part of the liver, as well as the reactions against $\mathrm{SbCl}_{3}, \mathrm{GDH}$, and $\mathrm{H}_{2} \mathrm{SO}_{4}$, as shown in Table $\mathrm{I}$, and further, from the change of the intensity of the fluorescence of vitamin granules according to the amount loaded, the method is considered to be a satisfactory one.

Since vitamin $\mathrm{D}$ granules were stained by $\mathrm{SbCl}_{3}, \mathrm{GDH}$, or $\mathrm{H}_{2} \mathrm{SO}_{4}$, the practical application of these reagents is conceivable but both $\mathrm{SbCl}_{3}$ and GDH remove vitamin D granules from the cells by dissolution; accordingly, the localization of the vitamin is hardly detected. Further, the treatment with $\mathrm{SbCl}_{3}$ necessiates manipulations in anhydrous media, as was discribed by the authors in the histochemical examination of vitamin A (4); the existence of a trace of water makes the preparation turbid. The GDH method has the weakness of too low sensitivity. Both reactions are disturbed by the existence of vitamin $A$. The $\mathrm{H}_{2} \mathrm{SO}_{4}$ method is too unspecific; the vitamin granules are not fixed, the preparations are liable to be damaged; accordingly, it is hardly applicable to histochemistry.

\section{Distribution and Fate of Vitamin $D$ in the Body.}

After administering vitamin $\mathrm{D}$ solution in oil to rats, distinct absorption pictures of the vitamin from the small intestine are obtained after 4-6 hours, whereas the absorption was not marked in the duodenum, suggesting a significant effect of bile upon the absorption of the vitamin. 
The vitamin absorbed from intestinal mucosa enters the blood circulation through central lacteals and lymph vessels, then it is brought from the small circulation to the general circulation and finally into the liver. In the liver, the vitamin is at first taken up by the liver cells around lobules, and reaches gradually the middle and center parts. Generally speaking, the vitamin is markedly deposited in the Kupffer cells when the amount of the vitamin surpasses the ability of the cells for taking up the vitamin and it is presumably esterified with fatty acids in the cells. It is also assumed that the excessive amount of the vitamin is taken up by the Kupffer cells in order to prevent its entrance into the general circulation. The same is also assumed to exist in reticuloendotheliar cells in the spleen.

The main storage organs of vitamin D are liver, adrenal glands and adipose tissues. Some storage of the vitamin is considered to take place also in lungs, spleen and bones.

Vitamin D is excreted from intestine and kidneys but some excretion is considered also to take place from liver cells into bile. In the intestinal canal some observations suggesting excretion besides absorption have also been made. The excretion from the large intestine was not marked. It is excreted chiefly from the small intestine.

The excretion from the kidneys was easily considerable from its tissue picture, but judging from the relatively difficult appearance in kidneys, the excretion of little vitamin D is assumed to occur largely from the intestinal tract; After loading with much vitamin, it is considered to be also excreted from the kidneys.

Vitamin D is easily deposited in the liver. However, after loading with much vitamin, it is excreted from liver cells to bile, which is then excreted in the intestinal tract via ductus choledochus. It is therefore considered that the vitamin $\mathrm{D}$ existing in the intestinal tract is the mixture of the vitamin in the intestinal tract and that excreted from the liver.

\section{SUMMARY}

A histochemical fluorescence-microscopic detection method of vitamin D was deviced and using this method the histological distribution picture of vitamin $\mathrm{D}$ in each organ was examined and from these hostological pictures the absorption, storage and excretion of vitamin D were discussed.

\section{REFERENCES}

1. Araki, M., and Chin, S., Vitamins 11, 253 (1956).

2. Seeger, P. G., Z. mikr. anat. Forsch. 48, 639 (1940).

3. Lison, L., Histochimie et Cytochimie Animales, Principles et Methodes. Paris, Gauthin-Villars (1953).

4. Araki, M., and Tsuji, S., Trans Soc. Path. Jap. 39, 124 (1950). 